\title{
Choice or opportunity: are post-release social groupings influenced by familiarity or reintroduction protocols?
}

\author{
K. E. Moseby, D. T. Blumstein, M. Letnic and R. West
}

\begin{abstract}
The conservation benefits of maintaining social groupings during and after animal translocations are unclear. Although some studies report improved post-release survival, others found no discernible influence on reintroduction success. Understanding the effects of social groupings is difficult because release methods can influence the animals' ability to maintain social groups. We explored this relationship by first studying whether release protocols influenced post-release cohesion in the communal burrowing bettong Bettongia lesueur, and then investigating whether maintenance of social cohesion conferred any post-release advantage. We released bettongs into a small ( $8 \mathrm{ha})$ and large (2,60o ha) area and compared the proportion that maintained social groupings in the different settings. The proportion of bettongs sharing with previous warren co-occupants was higher than expected by chance in both areas, however, a significantly higher proportion of bettongs maintained social groupings in the small $(75 \%)$ compared to the large release area (13\%). This suggests bettongs prefer to maintain social groupings but are unable to locate members of their group in large release areas. Bettongs that did maintain social groupings showed no difference in reproductive or health outcomes compared to those that formed new social groupings, suggesting no benefit to reintroduction success. We conclude that release protocols can influence post-release cohesion, but that greater cohesion does not necessarily confer advantages to groupliving animals. To test the importance of social cohesion, further research on reintroductions should compare postrelease parameters for animals released using protocols that do and do not facilitate maintenance of social groupings.
\end{abstract}

Keywords Australia, bettong, Bettongia lesueur, release protocols, social networks, translocation

K. E. Moseby* (Corresponding author), M. Letnic and R. West Centre for Ecosystem Science, School of Biological, Earth and Environmental Sciences, University of New South Wales, 2035 Sydney, Australia

E-mail k.moseby@unsw.edu.au

D. T. Blumstein Department of Ecology and Evolutionary Biology, University of California, Los Angeles, USA

${ }^{\star}$ Also at: Arid Recovery Ltd., Roxby Downs, Australia.

Received 28 September 2017. Revision requested 4 December 2017 Accepted 11 January 2018. First published online 22 August 2018.

\section{Introduction}

$\mathrm{M}$ any conservation reintroductions fail (Wolf et al., 1996; Fischer \& Lindenmayer, 2000; Short, 2009; Moseby et al., 2011) and protocols have been developed to improve reintroduction success (Batson et al., 2015) and reduce stress in translocated animals (Teixeira et al., 2007). Recent research suggests that release protocols should be tailored to particular species and sites (Moseby et al., 2014) and that selection of these protocols should be based on the biological needs of the animals and their response to the release. Previous studies have focused on factors such as size and composition of the release group (McCallum \& Timmers, 1995), provision of supplementary food or water, delayed vs immediate release (Letty et al., 2000; Matějů et al., 2012), and the location of source populations (Bright \& Morris, 1994; Soorae, 2010).

For social species, maintaining social bonds may be essential for successful translocation (Shier, 2006; Batson et al., 2015). Social disruption could cause higher stress, greater post-release dispersal and delayed breeding in gregarious species. Conversely, maintaining social or family groups could increase survival, reduce post-release stress, and promote faster establishment and breeding. Animals thought to require social groupings for survival, including large predators that hunt in packs, are often held together prior to reintroduction to enable social bonds to form (e.g. lions Panthera leo: Hayward et al., 2007; wild dogs Lycaon pictus: Davies-Mostert et al., 2009; Gusset et al., 2009), but the importance of pre-release housing is rarely tested empirically (but see review in Shier, 2016).

Results from studies that manipulate social groupings during reintroductions are mixed; releasing individuals in social groups had little benefit in New Zealand saddlebacks Philesturnus carunculatus (Armstrong \& Craig, 1995) or Australian tammar wallabies Macropus eugenii (Kemp et al., 2015). Social organization did not affect dispersal in white-tailed deer Odocoileus virginianus (Jones et al., 1997). However, studies on black-tailed prairie dogs Cynomys ludovicianus (Shier, 2006), brown treecreepers Climacteris picumnus (Bennett et al., 2012) and black-eared miners Manorina melanotis (Clarke et al., 2002) suggest that releasing animals in familiar groups helps maintain social cohesion and aids establishment and survival after release. Similarly, the failure of rock hyrax Procavia capensis reintroductions in South Africa was thought to be caused by failure to maintain social groupings after release and rock hyraxes 
that were not familiar with each other dispersed further following release (Wimberger et al., 2009).

Understanding the benefits of social groupings can be difficult because release methods may influence the ability of animals to maintain social groups. Releasing animals in social groups may not lead to group persistence after release because of post-release panic dispersal, new interactions with other conspecifics at the release site, post-release stress behaviour, or the absence of suitable shelter sites that can support the size of the social group. For example, although saddlebacks were released in social groups in New Zealand, they failed to maintain pair bonds after release, which could have been a direct result of the hard release method used (Armstrong \& Craig, 1995). To examine the benefits of social groups, we need to compare groups of animals that are released using methods that do and do not facilitate the maintenance of social groupings.

Thus, to understand the importance of social cohesion, we must consider the influence of release protocols on the maintenance of social groupings. In this study, we first tested the influence of release protocols on the maintenance of social groupings by releasing the burrowing bettong Bettongia lesueur into large and small release areas and comparing the proportion that maintained social cohesion. We then tested whether maintenance of social groupings conferred any post-release advantage by measuring health and reproductive parameters in groups that did and did not maintain social groupings. The burrowing bettong is a social marsupial, categorized as Near Threatened on the IUCN Red List, which lives in warrens consisting of related females and a dominant male (Sander et al., 1997). Bettongs are reported to have a weak dominance hierarchy, with older females occupying the upper ranks and young males the lower (Sander et al., 1997). Burrowing bettongs are small (c. $1.6 \mathrm{~kg}$ ) macropodids that feed on seeds, stems and roots of a variety of plants (Bice \& Moseby, 2008), and the only macropod to live exclusively in burrows (Short \& Turner, 1999). Under semi-captive conditions bettongs have been found to use several warrens but both sexes have one or two preferred warrens where they spend $24-100 \%$ of their time during the day (females $77 \%$ of time in one warren, males $44 \%$ of time in one warren; Sander et al., 1997). In the wild, warren fidelity is usually high; females were found to use a mean of 2.7 warrens over 6 months (Finlayson \& Moseby, 2004).

\section{Study area}

We conducted experimental releases at the Arid Recovery Reserve near Roxby Downs in northern South Australia (Fig. 1). The entire 12,300 ha reserve is fenced with a cat, fox and rabbit-proof netting fence and four threatened mammal species have been reintroduced into the Reserve since 1998 (Moseby et al., 2011). The burrowing bettong

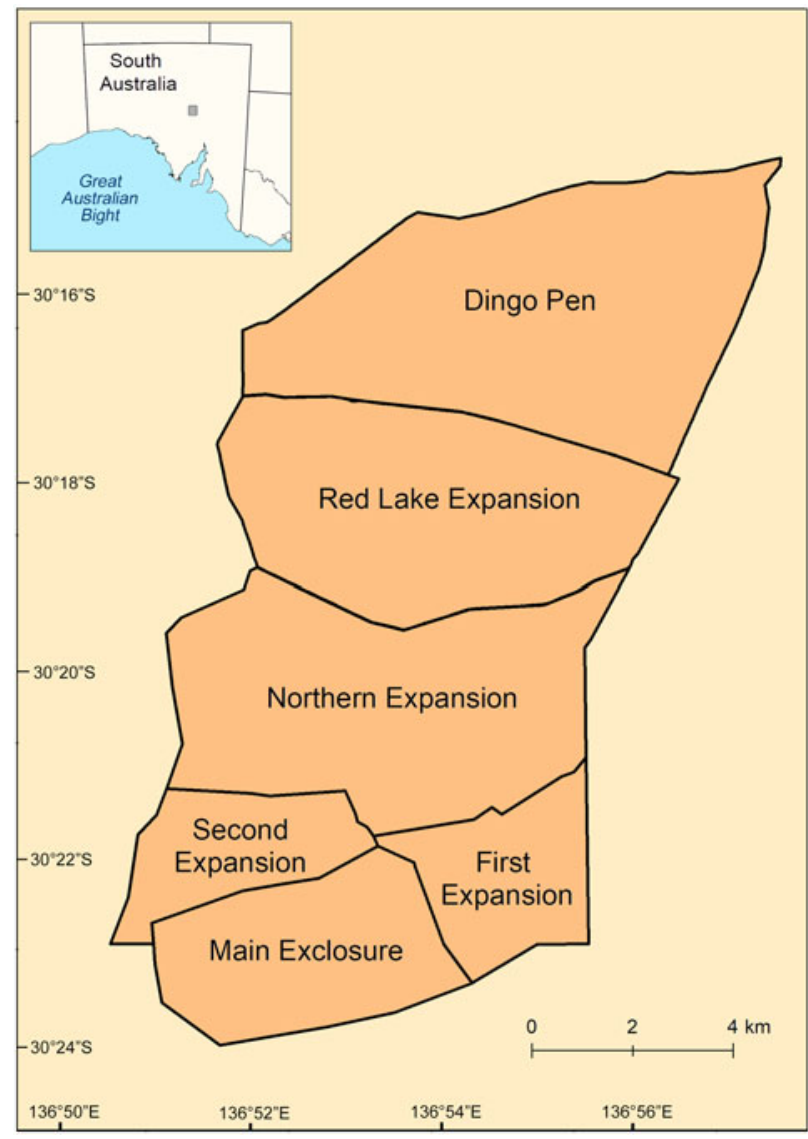

FIG. 1 Map of the Arid Recovery Reserve showing the source population (Main Exclosure) and the large release site (Red Lake Expansion) where bettongs were reintroduced. The small 8 ha release pen is located in the centre of the Main Exclosure. The location of the Reserve in Australia is shown on the inset map.

was reintroduced in 1999 from Western Australia and the population is now estimated at several thousand individuals.

The Reserve is divided into six paddocks. Rabbits Oryctolagus cuniculus, feral cats Felis catus and red foxes Vulpes vulpes have been removed from four paddocks totalling 6,00o ha. The remaining two are experimental paddocks containing rabbits and controlled densities of cats (i.e. cats are added to or removed from these areas to maintain a certain density; Moseby et al., 2018), but no foxes. Burrowing bettongs were first reintroduced to the 1,400 ha Main Exclosure and now occupy all four feral animal-free exclosures. Bettong abundance has increased since release and in 2014 we translocated bettongs between the feral animal-free Main Exclosure of the Reserve and the 2,60o ha Red Lake Expansion, one of the two experimental paddocks within the Reserve.

\section{Methods}

We first tested the influence of release protocols on the maintenance of social groupings by studying the social 
cohesion of burrowing bettongs released into the large fenced 2,60o ha Red Lake paddock and a smaller 8 ha release pen. We then determined whether the maintenance of social groupings affected body mass, body condition and reproductive condition in the large release area.

\section{Influence of release protocol: small release area}

In February 201615 bettongs were captured at five warrens in the Northern Expansion paddock and moved c. $6 \mathrm{~km}$ to an 8 ha, predator- and rabbit-free release pen in the Main Exclosure paddock (Fig. 1). Warrens in the Northern Expansion were $1 \mathrm{~km}$ apart and bettongs were released after dark at the same location within the 8 ha release pen. The release pen previously housed bettongs, but all bettongs were trapped and removed from the pen 3 weeks before the trial. There were six warrens in the release pen at the time of bettong removal but bettongs dig their own warrens within a few days if suitable shelter sites are not available.

To determine post-release social groupings, traps were set at each active warren or single entrance burrow $(n=14)$ within the release pen at 2 and 4 weeks after release. Traps were set immediately in front of warren entrances and checked within 2 hours of sunset, to decrease the chance of catching bettongs from other burrows. The number of bettongs sharing a warren after translocation was compared to the proportion expected by chance, using a Fishers Exact test.

\section{Influence of release protocol: large release area}

A total of 254 bettongs were translocated from the Main Exclosure to the Red Lake Expansion over 12 nights in October 2014. Animals were captured using groups of eight Sheffield cage traps set at 47 warrens for 1-4 nights. Cage traps were baited with a mixture of peanut butter and rolled oats. Warrens were $18-1,700 \mathrm{~m}$ apart in an area of 3,00o ha. All bettongs captured at a warren in a night were moved during the same night and multiple warrens were trapped per night. Bettongs with pouch young $>80 \mathrm{~mm}$ long were not moved but released at point of capture. Animals were transported $10 \mathrm{~km}$ from the Main Exclosure to the Red Lake Expansion and released in the dark. All bettongs were released at the same site near the centre of the Red Lake Expansion (Fig. 1). Capture bags were placed on the ground and untied, and bettongs were allowed to move off when ready.

To examine the social organization of bettongs in the study area, we radio-collared 54 bettongs in the Main Exclosure prior to translocation (25 g VHF core brass collars, Sirtrack, Havelock North, New Zealand). Bettongs were radio tracked at least once per week for up to 18 weeks, to record warren use and determine their resident warren (6-130 days, mean 78 days). During this period, 33 bettongs were also located during the day, and then followed for up to 3 nights to record the distance moved from their diurnal warren. This distance was averaged across all bettongs tracked at night to estimate the size of a bettong's neighbourhood; i.e. the linear distance from a resident warren where bettongs would probably be familiar with conspecifics. Twenty-five radio-collared bettongs were then captured and translocated with other individuals in October 2014 and monitored for up to 18 months after release.

During translocation, individuals were identified as warren co-occupants, neighbours or strangers based on the following criteria: warren co-occupants were individuals captured at the same warren on the night of translocation; neighbours were individuals captured at warrens within the neighbourhood distance of their warren; strangers were individuals captured at warrens outside their neighbourhood. To increase the chance of animals captured at the same warren being warren co-occupants rather than bettongs from adjacent warrens attracted to trap bait, we checked traps within $3 \mathrm{~h}$ of sunset when bettongs first emerged from their warrens and trapped multiple warrens in a neighbourhood simultaneously so that animals were likely to enter a trap at their own warren.

In March, June and October 2015 (3-10 months after initial release) warrens identified via radio-tracking of collared bettongs within the new translocation area in the Red Lake Expansion were trapped using the same methods as during translocation. The number of warren occupants was compared with the number of occupants recorded from warrens containing bettongs prior to the move. A total of 55 warrens were trapped over an 8-month period; 11 warrens in March 2015, eight warrens in both March and October 2015, 26 in June 2015 and 10 in October 2015. All individuals captured at the same warren were assumed to belong to the same social group.

The proportion of bettongs found sharing warrens after release was compared with the proportion expected by chance, to determine if bettongs exhibited a preference for maintaining social groupings. The number of burrow sharers expected by chance was calculated as the average number of burrow co-occupants after the move, divided by the total number of bettongs moved, multiplied by the number of original animals recaptured after the move. The proportion of recaptured individuals sharing in the small release pen was also compared with the proportion sharing in the large release area using a Fishers Exact Test.

To determine if social organization was broader than the individual warren level, we compared the distance between all pairs of bettongs before and after translocation using the distances between warrens where individuals were trapped before and after release. Individuals sharing a warren were considered to be o $\mathrm{m}$ apart. We found no more than two 
bettongs sharing a warren after release so we only compared the distance between all pairs of recaptured bettongs. The distances between pairs of bettongs before and after translocation were compared using a Mantel test (Smouse et al., 1986) which tests for a correlation in the pairwise distance matrix for before and after translocation. The Mantel test was computed in $R$ 3.3.2 using packages reshape2 (Wickham, 2007) and ade4 (Dray \& Dufour, 2007). We also compared the distance between previous warren co-occupants, neighbours and strangers after release using a one-way ANOVA.

\section{Influence of social groupings on post-release parameters}

All bettongs captured prior to release were given a unique ear tag, sexed and weighed, and their reproductive status was evaluated. Body condition was estimated using the formula condition = cube root weight/pes length (Short \& Turner, 2000). These parameters were compared before and after release for bettongs that did and did not maintain social groupings in the large release area, using two-way ANOVAs.

\section{Results}

\section{Social familiarity}

Of the 54 bettongs radio-collared before release, 15 (28\%) used the same warren over the study period, with the remaining bettongs using 2-4 different warrens a mean of $188.9 \pm \mathrm{SE} 40.4 \mathrm{~m}$ apart. The mean number of warrens used by all bettongs was 2.16 , with females using a mean of 1.8 \pm SE 0.15 warrens and males $2.1 \pm \mathrm{SE}$ 0.14. There was no significant difference between the number of warrens used by male and female bettongs $(F=1.58, \mathrm{df}=1$, $\mathrm{P}=0.215)$. A total of 89 night-time fixes were obtained from 25 radio-collared bettongs. The mean distance that bettongs travelled at night from their diurnal warren was $316 \pm$ SE $51.1 \mathrm{~m}$ (range 10.3-1,768 m).

\section{Influence of release protocol: small release area}

Fifteen bettongs were captured at the five warrens trapped during release into the small release area. After release, traps were set at the 14 warrens within the release pen and 10 of the 15 bettongs were captured in nine of these warrens (five individuals escaped the release pen by digging under the foot netting). Of the 10 recaptured animals, $6(60 \%, 2$ female-male pairs, and 1 male-male pair) shared warrens with a previous warren occupant 4 weeks after release. Two of the 10 recaptured bettongs did not have a previous burrow co-occupant to share with after release because their co-occupants escaped. This increased the proportion
TABLE 1 The number of bettongs captured at warrens containing radio-collared bettongs before (Main Exclosure) and after (Red Lake Expansion) translocation.

\begin{tabular}{lllll}
\hline Date & $\begin{array}{l}\text { Before/ } \\
\text { after }\end{array}$ & $\begin{array}{l}\text { Mean no. of } \\
\text { bettongs } \pm \text { SE }\end{array}$ & $\begin{array}{l}\text { Mean sex } \\
\text { ratio } \\
(\mathrm{F}: \mathrm{M}) \pm \mathrm{SE}\end{array}$ & $\begin{array}{l}\text { Total } \\
\text { warrens } \\
\text { trapped }\end{array}$ \\
\hline $\begin{array}{c}\text { October } \\
2014\end{array}$ & Before & $4.27 \pm 0.49$ & $0.42 \pm 0.05$ & 30 \\
$\begin{array}{c}\text { March } \\
2015\end{array}$ & After & $3.67 \pm 0.37$ & $0.35 \pm 0.05$ & 19 \\
$\begin{array}{c}\text { October } \\
2015\end{array}$ & After & $3.44 \pm 0.29$ & $0.31 \pm 0.05$ & 18 \\
\hline
\end{tabular}

of bettongs that maintained social groupings to $75 \%$ (6 out of 8 bettongs). Bettongs were significantly more likely to be sharing with a previous warren occupant compared to chance when escaped co-occupants were (Fisher Exact test statistic $=5.49, \mathrm{P}=0.019$ ) and were not included (Fisher Exact test statistic $=7.9, \mathrm{P}=0.005$ ).

\section{Influence of release protocol: large release area}

A total of 256 bettongs from 45 warrens were translocated from the Main Exclosure to the Red Lake Expansion over 12 nights in October 2014. Translocated radio-collared bettongs settled into warrens within 3 weeks of release, and we located 55 warrens in the new release area, using data from radio-collared bettongs and patrolling the area on foot. These warrens were located throughout the Red Lake Expansion and up to $5 \mathrm{~km}$ from the release site. Of the 254 bettongs translocated, 91 were recaptured and assigned warren occupancy. Trapping at warrens containing radiocollared animals revealed a mean of $4.27 \pm$ SE 0.49 bettongs per warren prior to translocation and $3.67 \pm \mathrm{SE} 0.37$ and 3.44 \pm SE 0.29 at 3 and 10 months post release, respectively (Table 1). There was no significant difference in the number of bettongs per warren $(F=0.980, \mathrm{df}=2, \mathrm{P}=0.381)$ or in the sex ratio of bettongs per warren $(F=1.307, \mathrm{df}=2, \mathrm{P}=0.278)$ before and after translocation. Only warrens known to be used by radio-collared bettongs were used in the analyses.

None of the 55 warrens trapped after release contained the same combination of occupants as prior to release. Only 12 individuals (6 pairs: 1 female-female, 1 malemale, 4 male-female) were still found to be sharing burrows with a previous co-occupant after release; 79 individuals shared with new co-occupants. Although only a small percentage $(13 \%)$ of bettongs were recaptured at warrens with a previous warren occupant, the proportion of individuals that maintained burrow sharing was still significantly higher than that expected by chance (two-tailed Fisher Exact Test Statistics $=7.74, \mathrm{P}=0.005$ ). The results from the Mantel test suggest that there was no relationship in the distances between all bettong pairs before and after translocation. Thus, post-release social groups were independent of 
TABLE 2 The distance between pairs of bettongs before and after release for pairs from the same burrow (co-occupants), from warrens within $316 \mathrm{~m}$ of each other (neighbours) and from warrens more than $316 \mathrm{~m}$ apart (strangers).

\begin{tabular}{llll}
\hline & $\begin{array}{l}\text { Distance before } \\
\text { move }(\mathrm{m})\end{array}$ & $\begin{array}{l}\text { Mean distance after } \\
\text { move }(\mathrm{m}) \pm \mathrm{SE}\end{array}$ & $\mathrm{N}$ \\
\hline Co-occupants & 0 & $2,117 \pm 123$ & 86 \\
Neighbours & $1-316$ & $2,081 \pm 90.7$ & 169 \\
Strangers & $>316$ & $2,250 \pm 22.3$ & 2,905 \\
\hline
\end{tabular}

pre-release social groups (Monte Carlo test observation $=0.005, \mathrm{P}=0.436)$. The mean distance between pairs of bettongs after release was c. $2 \mathrm{~km}$ and there was no significant difference in the distance between pairs of warren co-occupants, neighbours or strangers $(F=2.018, \mathrm{df}=2$, $\mathrm{P}=0.133$, Table 2).

Comparing the small and large release areas, we found that the proportion of bettongs sharing with previous warren co-occupants in the small release pen $(60 \%$ when including and $75 \%$ when excluding escaped co-occupants) was significantly higher than in the large release area (15\%) (compared to 60\%: Fisher Exact test statistic $=13.48$, $\mathrm{P}=0.002$; compared to $75 \%$ : Fisher Exact test statistic $=18.89$, $\mathrm{P}=0.00001)$.

When we trapped bettongs for relocation, we were not always able to trap all bettongs from a warren during the same night; warrens were trapped for up to 12 nights. Thus, to investigate the potential influence of the time between the first and second individual of a co-occupant pair being moved on the maintenance of social groupings, we compared co-occupant pairs that were moved during the same vs different nights $(1,4,6$ and $>7$ nights apart). Of the 86 warren co-occupants moved during the same or different nights, there was a significant effect of time between release of co-occupant pairs and their distance apart after release $(F=3.047, \mathrm{df}=4, \mathrm{P}=0.022$, Fig. 2). A Tukey post hoc test revealed that bettong pairs moved during the same night or 1 night apart were significantly closer after release than pairs moved $>7$ nights apart (Fig. 2).

\section{Influence of social groupings on post-release parameters}

Body mass, body condition and reproductive status of bettongs were compared before and 3 months after release between the individuals that maintained warren groupings vs those that did not. To exclude seasonal differences, only bettongs recaptured in March 2015 were included in this analysis. There was no significant difference between bettongs that did and did not maintain social groupings (Table 3 ). Body mass (2-way ANOVA $F=2.69, \mathrm{df}=3, \mathrm{P}=0.048$ ) and body condition index $(F=3.845, \mathrm{df}=3, \mathrm{P}=0.011)$ were significantly lower after release, but the non-significant interaction terms (mass $F=0.031, \mathrm{df}=1, \mathrm{P}=0.861$ and condition

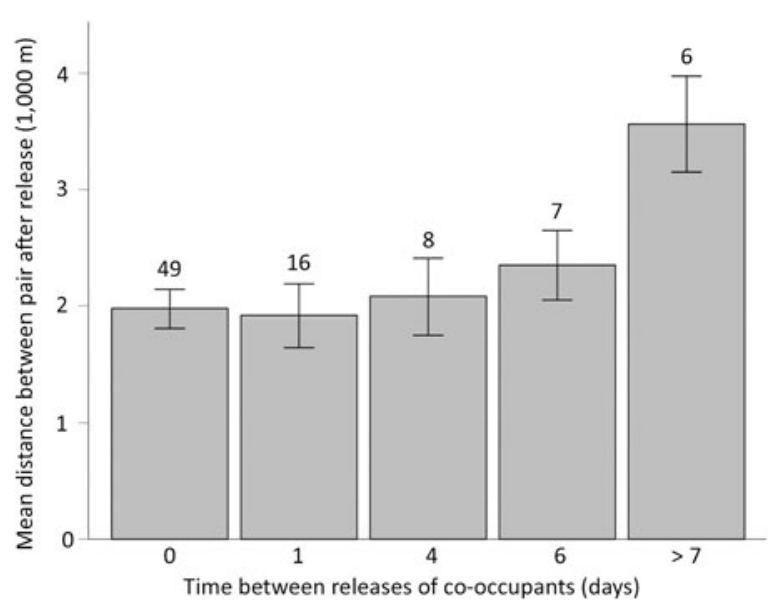

FIG. 2 Mean post-release distance \pm SE between pairs of previous warren co-occupants for different times between release of the first and second individual of each pair. Numbers above the bars represent the number of bettong pairs included for each bar.

$F=0.027, \mathrm{df}=1, \mathrm{P}=0.869)$ suggested this was consistent between the two groups. No females had pouch young when released and nearly all females had pouch young when trapped after release (Table 3). A Fisher Exact test found no significant difference in the proportion of females with pouch young in females who did and did not maintain social groupings (Fisher Exact Test Statistic $=1, \mathrm{P}>0.05$ ).

\section{Discussion}

The low percentage of bettongs that maintained social groupings after release into the large release area was unexpected considering they live communally in warrens with relatively high warren fidelity (Sander et al., 1997; Finlayson \& Moseby, 2004). Bettongs formed new social groupings soon after release, with a similar number of warren co-occupants to that recorded prior to translocation. Other studies have also reported a failure to maintain social bonds after release in species such as New Zealand robins (Armstrong, 1995) and rock hyraxes (Wimberger et al., 2009). Burrowing bettongs use more than one burrow within their home range and so it could be argued that social groupings may be more important at the neighbourhood rather than the individual warren level. However, we found that bettongs did not maintain neighbourhood associations after release; there was no significant difference in the distance after release of pairs of bettongs from the same neighbourhoods vs unfamiliar bettong pairs.

Although the maintenance of social groupings was low, it was still higher than that expected by chance and even higher in the small release pen, suggesting that bettongs sought to maintain social relationships after release and that the size of the release area influenced their ability to maintain social groupings. This is in contrast to other species such as the black-eared miner that appear to have strong group 
TABLE 3 Difference in body and reproductive condition 3 months after release for animals that maintained social groupings vs those that did not.

\begin{tabular}{lcll}
\hline & \% with pouch young $(\mathrm{n})$ & Mean body condition index \pm SE $(\mathrm{n})$ & Mean weight $(\mathrm{g}) \pm \mathrm{SE}(\mathrm{n})$ \\
\hline Maintained, before & $0(5)$ & $5.04 \pm 0.053(12)$ & $1,566 \pm 17.4(12)$ \\
Maintained, after & $100(5)$ & $4.74 \pm 0.053(12)$ & $1,486 \pm 17.4(12)$ \\
Non-maintained, before & $0(27)$ & $5.06 \pm 0.009(69)$ & $1,580 \pm 7.2(69)$ \\
Non-maintained, after & $93(27)$ & $4.68 \pm 0.009(69)$ & $1,472 \pm 7.2(69)$ \\
\hline
\end{tabular}

bonds, with populations maintaining social cohesion even in soft and hard releases (Clarke et al., 2002). Our finding that bettongs were significantly more likely to maintain social groupings after release into a small compared to a large release site suggests that the breakdown of social groupings in the large release site could have been caused by an inability of previous warren co-occupants to locate each other after release. Radio-collared bettongs usually settle into burrows within 7 days of release (Moseby et al., 2014), so in large release areas it is probable that bettongs settled into warrens with individuals that were in close proximity during the first days after release. Our observation that co-occupant pairs that were moved within a few days of each other were more likely to settle in warrens that were closer together than those released $>7$ days apart supports this finding.

Bettongs disperse up to $21 \mathrm{~km}$ after release (Short \& Turner, 2000; Moseby et al., 2011), which decreases the chance of intercepting warren co-occupants in the first few days after release, when warren occupancy is formed. Our findings are consistent with the hypothesis that this hyper-dispersal is facilitated by the opportunity to move long distances. By contrast, the small release site may have allowed bettongs to locate each other sooner and permitted them to maintain social bonds.

Importantly, social group fidelity seemed to confer no fitness advantages; the few individuals that maintained social groupings after release did no better than those that developed new social groupings. There were no significant differences in breeding rates, body condition or body mass of animals that maintained vs those that formed new social groupings. Thus, our results suggest that bettongs were not negatively affected by the breakdown of social groupings during reintroduction and were readily able to form new social groups.

These results are similar to other studies where social groupings were not maintained and new groupings were formed with no impact on post-release fitness correlates. Experimental trials with white-tailed deer found that individuals translocated in social or unrelated groups did not remain with their release groups but there was no difference in survival probability or dispersal distance from the release site in familiar vs unfamiliar groups (Jones et al., 1997). However, this is not always the case. For example, rock hyrax reintroductions failed because of an inability to maintain or form new social groupings following release (Wimberger et al., 2009) and prairie dog survival was improved when animals were released in their social groupings (Shier, 2006). We did not compare survival between groups but the time taken to form new social groupings could have increased bettong vulnerability to predators and may have affected survival if we had released animals into an area with high predator densities. Taken together, the variety of results suggests that the effects of transferring animals in social and non-social groups are species-specific and possibly related to the importance of social bonds for defence from predators, access to food or reproduction.

Burrowing bettongs appeared to prefer to maintain social groupings after release but readily formed new social groupings with no apparent detrimental effect on long-term reintroduction success. This suggests that release methods can influence the ability of animals to maintain social groupings but that maintaining social cohesion after release does not necessarily lead to fitness advantages. Thus the failure of animals to maintain social bonds in some release programmes could be an artefact of the release protocol rather than a result of the individual animals' preference. To understand the benefits of maintaining social groupings in reintroduction programmes, future translocations should first seek to examine the requirements for maintaining social groupings after release and then compare post-release parameters for groups of animals released using protocols that do and do not facilitate maintenance of social groupings. Only under these scenarios will it be possible to accurately determine the benefits of maintaining social groupings in reintroduction programmes.

Acknowledgements We thank D. Williams, R. Pedler, C. Lynch, P. Carter and Z. Richardson for assistance with fieldwork. Funding was obtained from an Australian Research Council Linkage Grant between Arid Recovery, University of New South Wales and University of California Los Angeles (Australian Research Council Linkage Project LP160100270). Arid Recovery is an independent conservation initiative supported by BHP Billiton, the University of Adelaide and the South Australian Department of Environment.

Author contributions Conception of the study: KM and RW. Methodology design: RW, KM, DTB and ML. Data collection: RW and KM. Data analysis: RW and KM. Writing: KM and RW. All authors interpreted the data, contributed to drafts and gave approval for publication.

\section{Conflicts of interest None.}


Ethical standards Ethics approval was obtained from the South Australian Wildlife Ethics committee, approval no. 1/2014M2.

\section{References}

Armstrong, D.P. (1995) Effects of familiarity on the outcome of translocations, II. A test using New Zealand robins. Biological Conservation, 71, 281-288.

Armstrong, D.P. \& Craig, J.L. (1995) Effects of familiarity on the outcome of translocations, I. A test using saddlebacks Philesturnus carunculatus rufusater. Biological Conservation, 71, 133-141.

Batson, W.G., Gordon, I.J., Fletcher, D.B. \& Manning, A.D. (2015) Translocation tactics: a framework to support the IUCN guidelines for wildlife translocations and improve the quality of applied methods. Journal of Applied Ecology, 52, 1598-1607.

Bennett, V.A., Doerr, V.A., Doerr, E.D., Manning, A.D., Lindenmayer, D.B. \& Yoon, H.-J. (2012) Habitat selection and post-release movement of reintroduced brown treecreeper individuals in restored temperate woodland. PLoS ONE, 7, e50612.

Bice, J. \& Moseby, K. (2008) Diets of the re-introduced greater bilby (Macrotis lagotis) and burrowing bettong (Bettongia lesueur) in the Arid Recovery Reserve, Northern South Australia. Australian Mammalogy, 30, 1-12.

Bright, P. \& Morris, P. (1994) Animal translocation for conservation: performance of dormice in relation to release methods, origin and season. Journal of Applied Ecology, 31, 699-708.

Clarke, R., Boulton, R. \& Clarke, M. (2002) Translocation of the socially complex black-eared miner Manorina melanotis: a trial using hard and soft release techniques. Pacific Conservation Biology, $8,223-234$.

Davies-Mostert, H.T., Mills, M.G.L. \& Macdonald, D.W. (2009) A critical assessment of South Africa's managed metapopulation recovery strategy for African wild dogs. In Reintroduction of Top-order Predators (eds M.W. Hayward \& M. J. Somers), pp. 10-42. Blackwell Publishing, Oxford, UK.

Dray, S. \& Dufour, A.B. (2007) The ade4 package: implementing the duality diagram for ecologists. Journal of Statistical Software, 22, 1-2O.

Finlayson, G.R. \& Moseby, K.E. (2004) Managing confined populations: the influence of density on the home range and habitat use of reintroduced burrowing bettongs (Bettongia lesueur). Wildlife Research, 31, 457-463.

Fischer, J. \& Lindenmayer, D.B. (2000) An assessment of the published results of animal relocations. Biological Conservation, 96, 1-11.

Gusset, M., Jаковy, O., Müller, M.S., Somers, M.J., Slotow, R. \& Grimm, V. (2009) Dogs on the catwalk: modelling re-introduction and translocation of endangered wild dogs in South Africa. Biological Conservation, 142, 2774-2781.

Hayward, M.W., Kerley, G.I., Adendorff, J., Moolman, L.C., O'brien, J., Sholto-Douglas, A. et al. (2007) The reintroduction of large carnivores to the Eastern Cape, South Africa: an assessment. Oryx, 41, 205-214.

Jones, M.L., Mathews, N.E. \& Porter, W.F. (1997) Influence of social organization on dispersal and survival of translocated female white-tailed deer. Wildlife Society Bulletin (1973-2006), 25, 272-278.

Kemp, L., Norbury, G., Groenewegen, R. \& Comer, S. (2015) The roles of trials and experiments in fauna reintroduction programs. In Advances in Reintroduction Biology of Australian and New Zealand Fauna (eds D. Armstrong, M. Hayward, D. Moro, \& P. Seddon), pp. 73-9o. CSIRO Publishing, Collingwood, Australia.
Letty, J., Marchandeau, S., Clobert, J. \& Aubineau, J. (eds) (2000) Improving Translocation Success: An Experimental Study of Anti-stress Treatment and Release Method for Wild Rabbits. Animal Conservation Forum, vol. 3. Cambridge University Press, Cambridge, UK.

Matějư, J., Říčanová, Š., Poláková, S., Ambros, M., Kala, B., Matějủ, K. \& Kratochvíl, L. (2012) Method of releasing and number of animals are determinants for the success of European ground squirrel (Spermophilus citellus) reintroductions. European Journal of Wildlife Research, 58, 473-482.

McCallum, H. \& Timmers, P. (1995) Modelling the impact of predation on reintroductions of bridled nailtail wallabies. Wildlife Research, 22, 163-171.

Moseby, K., Hill, B., Lavery, T. \& Slotow, R. (2014) Tailoring release protocols to individual species and sites: one size does not fit all. PLOS ONE, 9, e99753.

Moseby, K., Letnic, M., Blumstein, D. \& West, R. (2018). Designer prey: can controlled predation accelerate selection for anti-predator traits in naïve populations? Biological Conservation, 217, 213-221.

Moseby, K., Read, J., Paton, D., Copley, P., Hill, B. \& Crisp, H. (2011) Predation determines the outcome of 10 reintroduction attempts in arid South Australia. Biological Conservation, 144, 2863-2872.

SAnder, U., Short, J. \& Turner, B. (1997) Social organisation and warren use of the burrowing bettong, Bettongia lesueur (Macropodoidea: Potoroidae). Wildlife Research, 24, 143-157.

Shier, D. (2016) Manipulating Animal Behavior to Ensure Reintroduction Success. In Conservation Behavior: Applying Behavioral Ecology to Wildlife Conservation and Management (eds. O. Berger-Tal \& David Saltz), pp. 275-304. Cambridge University Press, Cambridge, UK.

SHIER, D.M. (2006) Effect of family support on the success of translocated black-tailed prairie dogs. Conservation Biology, 20, $1780-1790$.

Short, J. (2009) The Characteristics and Success of Vertebrate Translocations within Australia. Department of Agriculture, Fisheries and Forestry, Canberra, Australia.

Short, J. \& Turner, B. (1999) Ecology of burrowing bettongs, Bettongia lesueur (Marsupialia: Potoroidae), on Dorre and Bernier Islands, Western Australia. Wildlife Research, 26, 651-669.

Short, J. \& Turner, B. (200o) Reintroduction of the burrowing bettong Bettongia lesueur (Marsupialia: Potoroidae) to mainland Australia. Biological Conservation, 96, 185-196.

Smouse, P.E., LonG, J.C. \& Sokal, R.R. (1986) Multiple regression and correlation extensions of the Mantel test of matrix correspondence. Systematic Zoology, 35, 627-632.

Soorae, P.S. (2010) Global Re-introduction Perspectives: Additional Case Studies from Around the Globe. IUCN, Abu Dhabi, United Arab Emirates.

Teixeira, C.P., De Azevedo, C.S., Mendl, M., Cipreste, C.F. \& YounG, R.J. (2007) Revisiting translocation and reintroduction programmes: the importance of considering stress. Animal Behaviour, 73, 1-13.

Wicкнам, H. (2007) Reshaping data with the reshape package. Journal of Statistical Software, 21, 1-20.

Wimberger, K., Downs, C.T. \& Perrin, M.R. (2009) Two unsuccessful reintroduction attempts of rock hyraxes (Procavia capensis) into a reserve in the KwaZulu-Natal Province, South Africa. South African Journal of Wildlife Research, 39, 192-201.

Wolf, C.M., Griffith, B., Reed, C. \& Temple, S.A. (1996) Avian and mammalian translocations: update and reanalysis of 1987 survey data. Conservation Biology, 10, 1142-1154. 